\title{
A sub-1V high PSRR OpAmp based $\beta$-multiplier CMOS bandgap voltage reference with resistive division
}

\author{
Anass Slamti ${ }^{1}$, Youness Mehdaoui ${ }^{2}$, Driss Chenouni $^{3}$, Zakia Lakhliai $^{4}$ \\ ${ }^{1,2,3,4}$ Computer and Interdisciplinary Physics Laboratory (L.I.P.I.), USMBA, Morocco \\ ${ }^{2}$ Research team in Electronics, Instrumentation and Measurements, USMS, Morocco
}

\begin{abstract}
Article Info
ABSTRACT

Article history:

Received Oct 4, 2018

Revised Nov 17, 2018

Accepted Jan 2, 2019

\section{Keywords:}

Bandgap reference

Line regulation

OpAmp

Power supply rejection ratio

Temperature coefficient

A sub-1V opamp based $\beta$-multiplier CMOS bandgap voltage reference (BGVR) with high power supply rejection ratio (PSRR) and low temperature coefficient (TC) is proposed in this paper. A current mode regulator scheme is inserted to isolate the supply voltage of the operational amplifier (opamp) and the supply voltage of the BGVR core from the supply voltage source in order to reduce ripple sensitivity and to achieve a high PSRR. The proposed circuit is designed and simulated in $0.18-\mu \mathrm{m}$ standard CMOS technology. The proposed voltage reference delivers an output voltage of $634.6 \mathrm{mV}$ at $27^{\circ} \mathrm{C}$. Tthe measurement temperature coefficient is $22,3 \mathrm{ppm} /{ }^{\circ} \mathrm{C}$ over temperature range $-40^{\circ} \mathrm{C}$ to $140^{\circ} \mathrm{C}$, power supply rejection ratio is $-93 \mathrm{~dB}$ at $10 \mathrm{kHz}$ and $-71 \mathrm{~dB}$ at $1 \mathrm{MHz}$ and a line regulation of $104 \mu \mathrm{V} / \mathrm{V}$ is achieved over supply voltage range $1.2 \mathrm{~V}$ to $1.8 \mathrm{~V}$. The layout area of the proposed circuit is $0.0337 \mathrm{~mm} 2$. The proposed sub-1V bandgap voltage reference can be used as an internal voltage reference in low power LDO regulators and switching regulators.
\end{abstract}

Copyright $\odot 2019$ Institute of Advanced Engineering and Science. All rights reserved.

\section{Corresponding Author:}

Anass Slamti,

Computer and Interdisciplinary Physics Laboratory (L.I.P.I.),

USMBA, Fez, Morocco,

B.P 5206 Bensouda-Fez, (+212) 535655861

Email: slamti.anass@gmail.com

\section{INTRODUCTION}

Many analog and mixed integrated circuits, such as low dropout (LDO) regulators [1], switching regulators [2], analog-to-digital converters, digital-to-analog converters, smart sensors and other precise industrial control systems require a fixed voltage reference to be compared to for the sake of reliability and accuracy. This voltage reference also called bandgap voltage reference is a circuit used to generate a fixed voltage, VREF, that is in theory independent of the power supply voltage VDD (where VREF<VDD), temperature and process variations. The classical design of BGVR circuits has commonly an output voltage VREF around $1.25 \mathrm{~V}$ (close to the theoretical $1.17 \mathrm{~V}$ bandgap voltage of silicon at $0 \mathrm{~K}$ ) [3]-[6].

As the technology scales less than 350 nanometers, so do the supply voltages. Recently, the supply voltages tend to be in the range of $0.6 \mathrm{~V}-1.2 \mathrm{~V}$. The supply voltage scales with the technology, but the threshold voltage of the transistors does not scale at the same rate. This makes it difficult to incorporate classical design of bandgap voltage reference to operate properly in the low supply voltages. For the low voltage bandgap reference design many approaches have been proposed; resistive divider networks [7-9], current summing and a voltage summing circuits [10], transimpedance amplifier [11], dynamic threshold mosfets [12] and other work [13].

Recent applications such as image sensors using LDO regulators require an accutare voltage refrence with very large PSRR value not only in the low frequencies but also in the high frequencies. 
To achieve this performance, various works has been proposed [14-18], but the performances of these works are limited in terms of PSRR, especially in the high frequencies.

This work propose a novel technique to improve the value of PSRR of sub-1V bandgap voltage reference circuit which provides an output voltage reference VREF with low TC and high PSRR in wide frequency range compared with related works previously mentioned.

\section{CONVENTIONAL SUB-1V BANDGAP VOLTAGE REFERENCE}

The sub-1V bandgap voltage reference is an analog circuit that provides a stable output voltage less than $1 \mathrm{~V}$. This is achieved by adding a voltage, which is proportional to the absolute temperature (PTAT), to a base-emitter voltage of diode connected Bipolar Junction Transistor (BJT) NPN or PNP type which is a complementary to the absolute temperature (CTAT) in order to compensate for its first-order temperature dependency [19].

The conventional sub-1V bandgap voltage reference suitable for low power supply voltages is shown in Figure 1 [7]. He use an OpAmp based $\beta$-multiplier architecture with resistive division, where the operational amplifier (OpAmp) will form an inverted feedback loop to enforce the two input nodes $\mathrm{X}$ and $\mathrm{Y}$ of this OpAmp having the same voltages.

The current mirror is formed by the PMOS transistors M1, M2 and M3 having identical size, so that the currents flowing through this three transistors are the same. The $\beta$-multiplier consists of two diode connected NPN transistors Q1 and Q2, with their emitter area ratio being 1:K to provide the required temperature dependent voltage to make the voltage reference circuit.

The output voltage reference VREF is expressed as:

$$
\mathrm{V}_{\mathrm{REF}}=\frac{\mathrm{R}_{3}}{\mathrm{R}_{2}} \cdot\left(\mathrm{V}_{\mathrm{BE}_{1}}+\frac{\mathrm{R}_{2}}{\mathrm{R}_{1}} \mathrm{~V}_{\mathrm{T}} \ln \mathrm{K}+\frac{\mathrm{R}_{2}}{\mathrm{R}_{1}} \mathrm{~V}_{\mathrm{OS}}\right)
$$

Where, $\mathrm{V}_{\mathrm{BE}_{1}}$ is the base-emitter voltage of $\mathrm{BJT} \mathrm{Q}_{1}$ witch has a negative temperature coefficient and represents the CTAT voltage, and $\mathrm{V}_{\mathrm{T}}$ is the thermal voltage $\left(\mathrm{V}_{\mathrm{T}}=25.9 \mathrm{mV}\right.$ at $\left.300 \mathrm{~K}\right)$ expressed as :

$$
\mathrm{V}_{\mathrm{T}}=\frac{\mathrm{k}_{\mathrm{B}} \mathrm{T}}{\mathrm{q}}
$$

Where $\mathrm{k}_{\mathrm{B}}$ is the Boltzmann's Constant $\left(\mathrm{k}_{\mathrm{B}}=1.381 \times 10^{-23} \mathrm{~J} \cdot \mathrm{K}^{-1}\right)$, $\mathrm{q}$ is the electron's charge $\left(\mathrm{q}=1.602 \times 10^{-19} \mathrm{C}\right)$ and $\mathrm{T}$ is the absolute temperature.

$V_{\text {os }}$ presents the input offset voltage of the OpAmp.

$\mathrm{V}_{\mathrm{T}}$ has a positive temperature coefficient and represents the PTAT voltage. If we neglect the value of $V_{O S}$, the (1) becomes:

$$
\mathrm{V}_{\mathrm{REF}}=\frac{\mathrm{R}_{3}}{\mathrm{R}_{2}}\left(\mathrm{~V}_{\mathrm{BE}_{1}}+\frac{\mathrm{R}_{2}}{\mathrm{R}_{1}} \mathrm{~V}_{\mathrm{T}} \ln \mathrm{K}\right)
$$

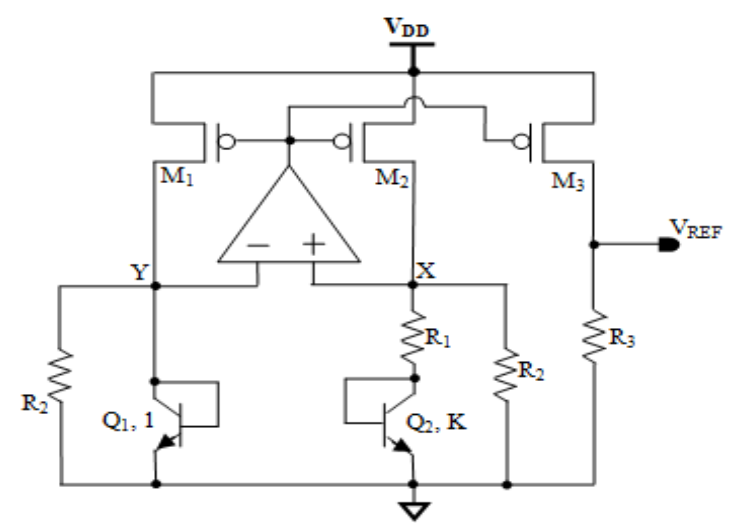

Figure 1. Schematic of Conventional sub-1V BGVR 
The temperature behavior of the $\mathrm{V}_{\mathrm{REF}}$ is:

$$
\frac{\partial \mathrm{V}_{\mathrm{REF}}}{\partial \mathrm{T}}=\frac{\mathrm{R}_{3}}{\mathrm{R}_{2}}\left[\frac{\partial \mathrm{V}_{\mathrm{BE}_{1}}}{\partial \mathrm{T}}+\frac{\mathrm{R}_{2}}{\mathrm{R}_{1}} \ln \mathrm{K}\left(\frac{\partial \mathrm{V}_{\mathrm{T}}}{\partial \mathrm{T}}\right)\right]
$$

A voltage reference independent of the absolute temperature is obtained if $\frac{\partial V_{\mathrm{REF}}}{\partial \mathrm{T}}=0$, then:

$$
\frac{\mathrm{R}_{2}}{\mathrm{R}_{1}} \ln \mathrm{K}=-\frac{\partial \mathrm{V}_{\mathrm{BE}_{1}} / \partial \mathrm{T}}{\partial \mathrm{V}_{\mathrm{T}} / \partial \mathrm{T}}
$$

Noted that $\frac{\partial \mathrm{V}_{\mathrm{BE}_{1}}}{\partial \mathrm{T}}<0$ and its value depends on the CMOS technology used and can be extracted by simulation, while $\frac{\partial \mathrm{V}_{\mathrm{T}}}{\partial \mathrm{T}}>0$ and it value can easily be calculated.

The conventional sub-1V BGVR using opamp $\beta$-multiplier architecture ensures a low temperature coefficient for $\mathrm{V}_{\mathrm{REF}}$ but remains very limited in terms of PSRR caused by the input offset voltage problem of the opamp, although some modifications have been proposed to improve the PSRR.

\section{PROPOSED SUB-1V BANDGAP VOLTAGE REFERENCE}

The schematic of proposed sub-1V BGVR is shown in Figure 2. A current mode regulator scheme is inserted to isolate a supply voltage of the opamp and supply voltage of the BGVR core from a supply voltage source $\mathrm{V}_{\mathrm{DD}}$ in order to reduce ripple sensitivity and to achieve a high PSRR.

The schematic of the opamp used is shown in Figure 3. A self biased cascode current mirror load is adopted to achieve a high gain [20]. This opamp needs a network compensation to achieve a sufficient phase margin in order to guarantee closed-loop stability. The supply voltage of the opamp is $\mathrm{V}_{\mathrm{REG}}$ which is equal to regulate source-drain voltage of $\mathrm{M}_{5}$. The proposed sub-1V BGVR needs a start-up circuit shown in Figure 4 to fix it at the proper operation point.

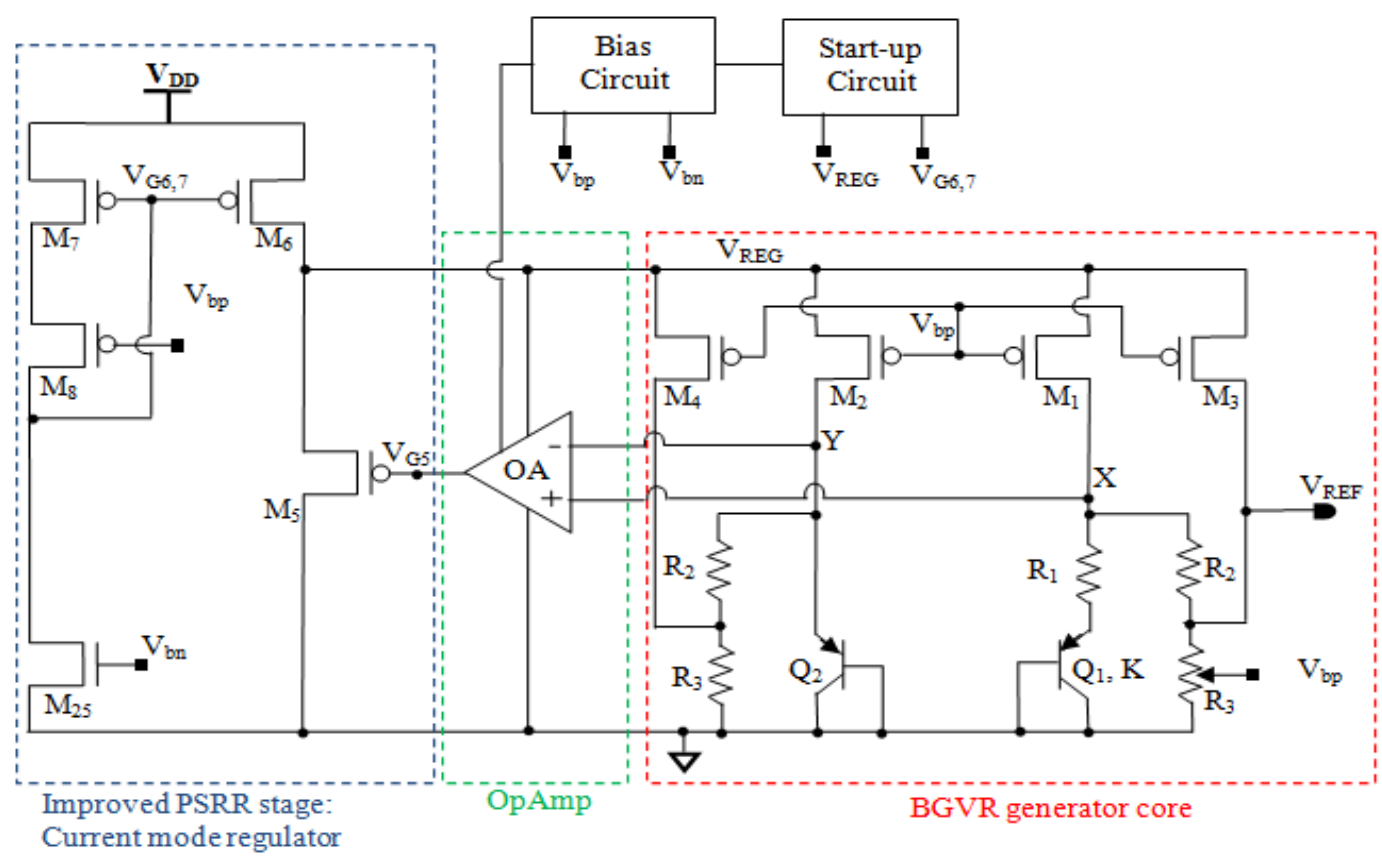

Figure 2. Schematic of proposed sub-1V BGVR 


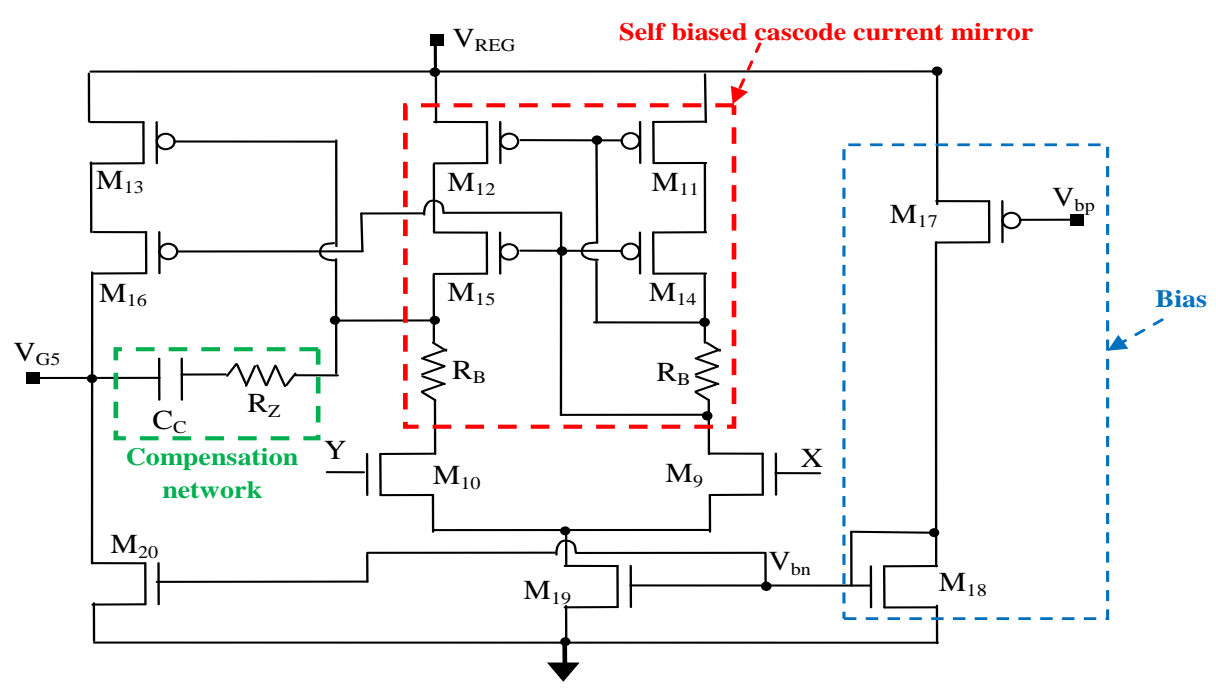

Figure 3. Schematic of opamp and his Bias circuit

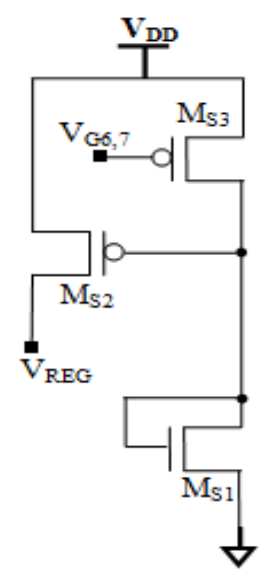

Figure 4. Schematic of start-up circuit

\subsection{Analysis and Design of Proposed BGVR Core}

The core of the proposed BGVR uses the same principle of the conventional scheme with some modifications on the resistive voltage divider in order to compensate the error introduced by the input offset voltage of the OpAmp and consequently to have the same voltage level in the $\mathrm{X}$ and $\mathrm{Y}$ nodes.

The PMOS transistors M1, M2, M3 and M4 have identical size, such that the currents flowing through this four transistors are the same as $I_{D_{1}}=I_{D_{2}}=I_{D_{3}}=I_{D}$. The $\beta$-multiplier consists of two diode connected PNP transistors Q1 and Q2, with their emitter area ratio being K:1 to provide the required temperature dependent voltage to construct the voltage reference circuit.

Let us establish the literal expression of the reference voltage VREF generated, we have:

$$
\mathrm{V}_{\mathrm{REF}}=\mathrm{R}_{3} \mathrm{I}_{\mathrm{R}_{3}}
$$

Where $I_{R_{3}}$ is the current flowing through the resistor R3, it is expressed as:

$$
\mathrm{I}_{\mathrm{R}_{3}}=\mathrm{I}_{\mathrm{R}_{2}}+\mathrm{I}_{\mathrm{D}}
$$

Where $I_{R_{2}}$ is the current flowing through the resistor R2, it is expressed as: 


$$
\mathrm{I}_{\mathrm{R}_{2}}=\frac{\mathrm{V}_{\mathrm{R}_{2}}}{\mathrm{R}_{2}}
$$

Where $\mathrm{V}_{\mathrm{R}_{2}}$ is the voltage across the resistor $\mathrm{R} 2$.

We also have:

$$
\mathrm{I}_{\mathrm{D}}=\mathrm{I}_{\mathrm{R}_{1}}+\mathrm{I}_{\mathrm{R}_{2}}
$$

And,

$$
\mathrm{R}_{1} \mathrm{I}_{\mathrm{R}_{1}}+\mathrm{V}_{\mathrm{EB}_{1}}=\mathrm{V}_{\mathrm{EB}_{2}}
$$

Where $\mathrm{VB}_{2}$ is the base-emitter voltage of PNP transistor Q2, it is expressed as:

$$
\mathrm{V}_{\mathrm{EB}_{2}}=\mathrm{V}_{\mathrm{T}} \ln \left(\frac{\mathrm{I}_{\mathrm{C}_{2}}}{\mathrm{I}_{\mathrm{S}_{2}}}\right)
$$

Where $\mathrm{I}_{\mathrm{S}_{2}}$ is the transport saturation current of $\mathrm{Q}_{2}$, expressed as:

$$
\mathrm{I}_{\mathrm{S}_{2}}=\mathrm{J}_{\mathrm{S}_{2}} \mathrm{~A}_{\mathrm{E}_{2}}
$$

Where $J_{S_{2}}$ is the saturation current density of $Q_{2}$ and $A_{E_{2}}$ is the emitter area of $Q 2$ and $V_{E_{1}}$ is the baseemitter voltage of PNP transistor $\mathrm{Q}_{1}$, expressed as:

$$
\mathrm{V}_{\mathrm{EB}_{1}}=\mathrm{U}_{\mathrm{T}} \cdot \ln \left(\frac{\mathrm{I}_{\mathrm{C}_{1}}}{\mathrm{I}_{\mathrm{S}_{1}}}\right)
$$

Where $I_{S_{1}}$ is the transport saturation current of $Q_{1}$, expressed as:

$$
\mathrm{I}_{\mathrm{S}_{1}}=\mathrm{J}_{\mathrm{S}_{1}} \mathrm{~A}_{\mathrm{E}_{1}}
$$

Where $J_{S_{1}}$ is the saturation current density of $Q_{1}$ and $A_{E_{1}}$ is the emitter area of $Q_{1}$.

We have:

$$
\mathrm{A}_{\mathrm{E}_{1}}=\mathrm{KA}_{\mathrm{E}_{2}}
$$

The transistors $\mathrm{Q}_{1}$ and $\mathrm{Q}_{2}$ have the same transport saturation current, as a result, the saturation current density $\mathbf{J}_{\mathrm{S}_{1}}$ is $\mathrm{K}$ times larger than the saturation current density $\mathbf{J}_{\mathrm{S}_{2}}$. By substituting (11), (12), (13), (14) and (15) in (10), we find:

$$
\mathrm{I}_{\mathrm{R}_{1}}=\frac{\mathrm{V}_{\mathrm{T}} \ln \mathrm{K}}{\mathrm{R}_{1}}
$$

Note that the current $\mathrm{I}_{\mathrm{R}_{1}}$ forms the PTAT current and is usually symbolized by IPTAT.

We also have:

$$
\mathrm{V}_{\mathrm{R}_{2}}=\mathrm{V}_{\mathrm{EB}_{2}}-\mathrm{V}_{\mathrm{REF}}
$$


By substituting (7), (8), (9) and (17) in (6), we find:

$$
\mathrm{V}_{\mathrm{REF}}=\mathrm{K}_{\mathrm{R}}\left(\mathrm{V}_{\mathrm{EB}_{2}}+\frac{\mathrm{R}_{2}}{2 \mathrm{R}_{1}} \mathrm{~V}_{\mathrm{T}} \ln \mathrm{K}\right)
$$

With,

$$
K_{R}=\frac{2 R_{3}}{R_{2}+2 R_{3}}
$$

If we take into account the input offset voltage $\mathrm{V}_{O S}$, we have $\mathrm{V}_{\mathrm{X}}=\mathrm{V}_{\mathrm{Y}}+\mathrm{V}_{\mathrm{OS}}$. Thus the expression of $\mathrm{V}_{\mathrm{REF}}$ becomes:

$$
\mathrm{V}_{\mathrm{REF}}=\mathrm{K}_{\mathrm{R}}\left(\mathrm{V}_{\mathrm{EB}_{2}}+\frac{\mathrm{R}_{2}}{2 \mathrm{R}_{1}} \mathrm{~V}_{\mathrm{T}} \ln \mathrm{K}+\frac{\mathrm{R}_{2}}{2 \mathrm{R}_{1}} \mathrm{~V}_{\mathrm{OS}}\right)
$$

As shown in (20) showns that the factor amplifying the input offset voltage is reduced in half in proposed circuit compared to that of the conventional scheme see (1).

Differentiating (19) with respect to absolute temperature yields:

$$
\frac{\partial \mathrm{V}_{\mathrm{REF}}}{\partial \mathrm{T}}=\mathrm{K}_{\mathrm{R}}\left[\frac{\partial \mathrm{V}_{\mathrm{EB}_{2}}}{\partial \mathrm{T}}+\frac{\mathrm{R}_{2}}{2 \mathrm{R}_{1}} \ln \mathrm{K}\left(\frac{\partial \mathrm{V}_{\mathrm{T}}}{\partial \mathrm{T}}\right)\right]
$$

To achieve a near-zero TC of VREF, $\frac{\partial \mathrm{V}_{\mathrm{REF}}}{\partial \mathrm{T}}=0$. Thus,

$$
\frac{\mathrm{R}_{2}}{2 \mathrm{R}_{1}} \ln \mathrm{K}=-\frac{\partial \mathrm{V}_{\mathrm{EB}_{1}} / \partial \mathrm{T}}{\partial \mathrm{V}_{\mathrm{T}} / \partial \mathrm{T}}
$$

For the CMOS technology used in our design, $\frac{\partial \mathrm{V}_{\mathrm{EB}_{2}}}{\partial \mathrm{T}} \approx 1.89 \mathrm{mV} /{ }^{\circ} \mathrm{C}$, and by using (2), we have $\frac{\partial \mathrm{V}_{\mathrm{T}}}{\partial \mathrm{T}}=\frac{\mathrm{k}_{\mathrm{B}}}{\mathrm{q}} \approx 0.0862 \mathrm{mV} /{ }^{\circ} \mathrm{C}$, from where we get:

$$
\frac{\mathrm{R}_{2}}{2 \mathrm{R}_{1}} \ln \mathrm{K}=21.9
$$

The value of $\mathrm{K}$ is set to 8 , thus:

$$
\mathrm{R}_{2}=21 \mathrm{R}_{1}
$$

Note that the final values of the resistances calculated by the hand must be adjusted during the design of the circuit to obtain an optimal value of the temperature coefficient of $V_{\text {REF }}$ over the required temperature range.

The minimum supply voltage to ensure proper operation of the proposed circuit and obtain an output voltage reference $\mathrm{V}_{\mathrm{REF}}$ less than $1 \mathrm{~V}$ with a small variation in the required temperature range is such that the following two constraints are met:

$$
\mathrm{V}_{\mathrm{DD}} \geq \mathrm{V}_{\mathrm{REF}}+\mathrm{V}_{\mathrm{SD}_{\mathrm{sat} 3,4}}+\mathrm{V}_{\mathrm{SD}_{\mathrm{sat} 6,7}}
$$

And, 


$$
\mathrm{V}_{\mathrm{DD}} \geq \mathrm{V}_{\mathrm{EB}_{2}}+\mathrm{V}_{\mathrm{SD}_{\text {sat } 1,2}}+\mathrm{V}_{\mathrm{SD}_{\mathrm{sat}, 7}}
$$

Where $\mathrm{V}_{\mathrm{SD}_{\text {sat } 3,4}}$ is the overdrive voltage of $\mathrm{M}_{3}$ and $\mathrm{M}_{4}, \mathrm{~V}_{\mathrm{SD}_{\text {sat } 1,2}}$ is the overdrive voltage of $\mathrm{M}_{1}$ and $\mathrm{M}_{2}$ and $\mathrm{V}_{\mathrm{SD}_{\text {sat } 6,7}}$ is the overdrive voltage of $\mathrm{M}_{6}$ and $\mathrm{M}_{7}$.

\subsection{PSRR Analysis}

In order to reduce ripple from the supply voltage which directly influences the performance of the PSRR, a pre-regulation stage is added to isolate the supply voltage VDD from both the supply voltage of the operational amplifier and the supply voltage of the BGVR core generator.

To establish the expression of the PSRR, the high frequency small signal model of the proposed circuit is realised see Figure 5. For the calculation of the PSRR, a similar method to that adopted in [21], is applied. The body effect is ignored and both Q1 and Q2 BJT transistors can be considered as short-circuited.

The voltage vdif shown in Figure 5 is the small signal part of the differential input voltage of the OpAmp.

We have:

$$
\operatorname{PSRR}(\mathrm{s})=\frac{\mathrm{v}_{\mathrm{dd}}(\mathrm{s})}{\mathrm{v}_{\text {ref }}(\mathrm{s})}
$$

Where $\mathrm{v}_{\mathrm{dd}}(\mathrm{s})$ is the high frequency small signal part of $\mathrm{V}_{\mathrm{DD}}, \mathrm{v}_{\mathrm{ref}}(\mathrm{s})$ is the high frequency small signal part of $\mathrm{V}_{\mathrm{REF}}$ and $\mathrm{s}$ is the complex variable of Laplace.

We can write that:

$$
\operatorname{PSRR}(\mathrm{s})=\frac{\mathrm{v}_{\mathrm{dd}}(\mathrm{s})}{\mathrm{v}_{\text {reg }}(\mathrm{s})} \times \frac{\mathrm{v}_{\text {reg }}(\mathrm{s})}{\mathrm{v}_{\text {ref }}(\mathrm{s})}
$$

Where $\mathrm{v}_{\text {reg }}(\mathrm{s})$ is the high frequency small signal part of $\mathrm{V}_{\mathrm{REG}}$. For a simple notation the variable $\mathrm{s}$ is omitted in the voltages symbols.

In the node $\mathrm{D}_{3}$, the Kirchhoff's Current Law gives:

$$
\left(\mathrm{g}_{\mathrm{m}_{3}}+\mathrm{Y}_{3}\right) \mathrm{v}_{\mathrm{reg}}+\mathrm{R}_{2}^{-1} \mathrm{v}_{\mathrm{d} 1}=\left(\mathrm{Y}_{3}+\mathrm{Y}_{11}+\mathrm{R}_{2}^{-1}\right) \mathrm{v}_{\mathrm{ref}}
$$

Where, $\mathrm{v}_{\mathrm{d} 1}$ is the high frequency small signal part of $\mathrm{V}_{\mathrm{D} 1}$, and,

$$
\begin{aligned}
& \mathrm{Y}_{3}=\mathrm{g}_{03}+\mathrm{C}_{\mathrm{ds} 3} \mathrm{~s} \\
& \mathrm{Y}_{11}=\mathrm{R}_{3}^{-1}+\mathrm{C}_{\mathrm{gd} 3} \mathrm{~s}
\end{aligned}
$$

In the node $\mathrm{D}_{1}$, the Kirchhoff's Current Law gives:

$$
v_{d 1}=\frac{\left(g_{m_{1}}+Y_{1}\right)}{\left(Y_{1}+Y_{10}+R_{2}^{-1}\right)} v_{r e g}+\frac{R_{2}^{-1}}{\left(Y_{1}+Y_{10}+R_{2}^{-1}\right)} v_{\text {ref }}
$$

Where,

$$
\begin{aligned}
& \mathrm{Y}_{1}=\mathrm{g}_{01}+\mathrm{C}_{\mathrm{ds} 1} \mathrm{~s} \\
& \mathrm{Y}_{10}=\mathrm{R}_{1}^{-1}+\mathrm{C}_{\mathrm{gd} 1} \mathrm{~s}
\end{aligned}
$$

By substituting (32) in (29), we obtain: 


$$
\frac{\mathrm{v}_{\text {reg }}}{\mathrm{v}_{\text {ref }}}=\frac{\mathrm{N}_{1}(\mathrm{~s})}{\mathrm{D}_{1}(\mathrm{~s})}
$$

Where,

$$
\begin{aligned}
& \mathrm{N}_{1}(\mathrm{~s})=\left(\mathrm{g}_{\mathrm{m} 3}+\mathrm{Y}_{3}\right) \cdot\left(\mathrm{Y}_{1}+\mathrm{Y}_{10}+\mathrm{R}_{2}^{-1}\right)+\mathrm{R}_{2}^{-1} \cdot\left(\mathrm{g}_{\mathrm{m} 1}+\mathrm{Y}_{1}\right) \\
& \mathrm{D}_{1}(\mathrm{~s})=\left(\mathrm{Y}_{3}+\mathrm{Y}_{11}\right)\left(\mathrm{Y}_{1}+\mathrm{Y}_{10}+\mathrm{R}_{2}^{-1}\right)+\mathrm{R}_{2}^{-1}\left(\mathrm{Y}_{1}+\mathrm{Y}_{11}\right)
\end{aligned}
$$

In the node $\mathrm{D}_{6}$, the Kirchhoff's Current Law gives:

$$
\mathrm{N}_{4}(\mathrm{~s}) \mathrm{v}_{\text {reg }}=\mathrm{Y}_{4} \mathrm{v}_{\mathrm{d} 4}+\mathrm{Y}_{1} \mathrm{v}_{\mathrm{d} 1}+\mathrm{Y}_{3} \mathrm{v}_{\mathrm{ref}}+\left(\mathrm{g}_{\mathrm{m} 5}+\mathrm{Y}_{6}\right) \mathrm{v}_{\mathrm{dd}}+\left(\mathrm{g}_{\mathrm{m} 6}+\mathrm{C}_{\mathrm{gd} 6} \mathrm{~s}\right) \mathrm{v}_{\mathrm{g} 6}+\left(\mathrm{g}_{\mathrm{m} 5}+\mathrm{C}_{\mathrm{gs} 5} \mathrm{~s}\right) \mathrm{v}_{\mathrm{g} 5}
$$

Where,

$$
\begin{aligned}
& \mathrm{N}_{4}(\mathrm{~s})=\left[\mathrm{g}_{\mathrm{mT}}+\mathrm{Y}_{\mathrm{T}}+\mathrm{g}_{\mathrm{m} 5}+\mathrm{Y}_{5}+\mathrm{Y}_{6}+\left(\mathrm{C}_{\mathrm{gd} 6}+\mathrm{C}_{\mathrm{gs} 5}+\mathrm{C}_{4}\right) \mathrm{s}\right] \\
& \mathrm{g}_{\mathrm{mT}}=\mathrm{g}_{\mathrm{m} 1}+\mathrm{g}_{\mathrm{m} 2}+\mathrm{g}_{\mathrm{m} 3}+\mathrm{g}_{\mathrm{m} 4} \\
& \mathrm{Y}_{\mathrm{T}}=\mathrm{Y}_{1}+\mathrm{Y}_{2}+\mathrm{Y}_{3}+\mathrm{Y}_{4} \\
& \mathrm{Y}_{2}=\mathrm{g}_{02}+\mathrm{C}_{\mathrm{ds} 2} \mathrm{~s} \\
& \mathrm{Y}_{4}=\mathrm{g}_{04}+\mathrm{C}_{\mathrm{ds} 4} \mathrm{~s} \\
& \mathrm{Y}_{5}=\mathrm{g}_{05}+\mathrm{C}_{\mathrm{ds} 5} \mathrm{~s} \\
& \mathrm{Y}_{6}=\mathrm{g}_{04}+\mathrm{C}_{\mathrm{ds} 6} \mathrm{~s} \\
& \mathrm{C}_{4}=\mathrm{C}_{\mathrm{gs} 1}+\mathrm{C}_{\mathrm{gs} 2}+\mathrm{C}_{\mathrm{gs} 3}+\mathrm{C}_{\mathrm{gs} 4}+\mathrm{C}_{\mathrm{bs} 1}+\mathrm{C}_{\mathrm{bs} 2}+\mathrm{C}_{\mathrm{bs} 3}+\mathrm{C}_{\mathrm{bs} 4}
\end{aligned}
$$

And, $\mathrm{v}_{\mathrm{d} 4}$ is the high frequency small signal part of $\mathrm{V}_{\mathrm{D} 4}, \mathrm{v}_{\mathrm{g} 5}$ is the high frequency small signal part of $\mathrm{V}_{\mathrm{G} 5}$ and $\mathrm{V}_{\mathrm{g} 6}$ is the high frequency small signal part of $\mathrm{V}_{\mathrm{G} 6}$.

In the node $\mathrm{D}_{4}$, the Kirchhoff's Current Law gives:

$$
\mathrm{v}_{\mathrm{d} 4}=\frac{\left(\mathrm{g}_{\mathrm{m}_{4}}+\mathrm{Y}_{4}\right)}{\left(\mathrm{Y}_{1}+\mathrm{Y}_{9}\right)} \mathrm{v}_{\mathrm{reg}}
$$

Where,

$$
\mathrm{Y}_{9}=\left(\mathrm{R}_{2} / / \mathrm{R}_{3}\right)^{-1}+\mathrm{C}_{\mathrm{gd} 4} \mathrm{~S}
$$

In the node $\mathrm{G}_{5}$, the Kirchhoff's Current Law gives:

$$
\mathrm{v}_{\mathrm{g} 5}=\frac{\mathrm{A}_{\mathrm{v}}}{\mathrm{r}_{\text {out }}\left[\mathrm{Y}_{\text {out }}+\left(\mathrm{C}_{\mathrm{gd} 5}+\mathrm{C}_{\mathrm{gs} 5}\right) \mathrm{s}\right]} \mathrm{v}_{\mathrm{d} 1}+\frac{\mathrm{C}_{\mathrm{gs} 5} \mathrm{~s}}{\left[\mathrm{Y}_{\text {out }}+\left(\mathrm{C}_{\mathrm{gd} 5}+\mathrm{C}_{\mathrm{gs} 5}\right) \mathrm{s}\right]} \mathrm{v}_{\text {reg }}
$$

Where, $A_{v}$ is the open-loop gain of the opamp, $r_{\text {out }}$ is its output resistance, $C_{\text {out }}$ is all capacitance connected from the output of the opamp to ground and, 


$$
\mathrm{Y}_{\text {out }}=\mathrm{r}_{\text {out }}^{-1}+\mathrm{C}_{\text {out }} \mathrm{s}
$$

In the node G6, the Kirchhoff's Current Law gives:

$$
\left[\mathrm{Y}_{\mathrm{b}}+\left(\mathrm{C}_{1}+\mathrm{C}_{\mathrm{gd} 6}\right) \mathrm{s}\right] \mathrm{v}_{\mathrm{g} 6}=\mathrm{C}_{1} \mathrm{sv}_{\mathrm{dd}}+\mathrm{C}_{\mathrm{gd} 6} \mathrm{v}_{\mathrm{reg}}+\left(\mathrm{g}_{\mathrm{m} 8}+\mathrm{Y}_{8}\right) \mathrm{v}_{\mathrm{s} 8}
$$

Where, $\mathrm{v}_{\mathrm{s} 8}$ is the high frequency small signal part of $\mathrm{V}_{\mathrm{S} 8}$ and,

$$
\mathrm{Y}_{\mathrm{b}}=\mathrm{R}_{\mathrm{b}}^{-1}+\mathrm{C}_{\mathrm{gd} 8} \mathrm{~S}
$$

Where $\mathrm{R}_{\mathrm{b}}$ represent the output resistance of current source bias network and,

$$
\begin{aligned}
& \mathrm{C}_{1}=\mathrm{C}_{\mathrm{gs} 6}+\mathrm{C}_{\mathrm{gs} 7}+\mathrm{C}_{\mathrm{bs} 6}+\mathrm{C}_{\mathrm{bs} 7} \\
& \mathrm{Y}_{8}=\mathrm{g}_{08}+\mathrm{C}_{3} \mathrm{~s} \\
& \mathrm{C}_{3}=\mathrm{C}_{\mathrm{ds} 8}+\mathrm{C}_{\mathrm{gd} 7}
\end{aligned}
$$

In the node $S_{8}$, the Kirchhoff's Current Law gives:

$$
v_{s 8}=\frac{\left(g_{m 7}+Y_{7}\right)}{\left(g_{m 8}+Y_{8}+Y_{7}+C_{2} s\right)} v_{d d}+\frac{\left(Y_{8}-g_{m 7}\right)}{\left(g_{m 8}+Y_{8}+Y_{7}+C_{2} s\right)} v_{g 6}
$$

Where,

$$
\mathrm{C}_{2}=\mathrm{C}_{\mathrm{gs} 8}+\mathrm{C}_{\mathrm{ds} 8}
$$

By substituting (56) in (51), we obtain:

$$
\mathrm{v}_{\mathrm{g} 6}=\frac{\mathrm{N}_{2}(\mathrm{~s})}{\mathrm{D}_{2}(\mathrm{~s})} \mathrm{v}_{\mathrm{dd}}+\frac{\mathrm{N}_{3}(\mathrm{~s})}{\mathrm{D}_{2}(\mathrm{~s})} \mathrm{v}_{\mathrm{reg}}
$$

Where,

$$
\begin{aligned}
& \mathrm{N}_{2}(\mathrm{~s})=\mathrm{C}_{1} \mathrm{~s}\left(\mathrm{~g}_{\mathrm{m} 8}+\mathrm{Y}_{7}+\mathrm{Y}_{8}+\mathrm{C}_{2} \mathrm{~s}\right)+\left(\mathrm{g}_{\mathrm{m} 8}+\mathrm{Y}_{8}\right)\left(\mathrm{g}_{\mathrm{m} 7}+\mathrm{Y}_{7}\right) \\
& \mathrm{N}_{3}(\mathrm{~s})=\mathrm{C}_{\mathrm{gd} 6} \mathrm{~s}\left(\mathrm{~g}_{\mathrm{m} 8}+\mathrm{Y}_{7}+\mathrm{Y}_{8}+\mathrm{C}_{2} \mathrm{~s}\right) \\
& \left.\mathrm{D}_{2}(\mathrm{~s})=\left[\mathrm{Y}_{\mathrm{b}}+\left(\mathrm{C}_{1}+\mathrm{C}_{\mathrm{gd} 6}\right) \mathrm{s}\right)\right]\left(\mathrm{g}_{\mathrm{m} 8}+\mathrm{Y}_{8}+\mathrm{Y}_{7}+\mathrm{C}_{2} \mathrm{~s}\right)+\left(\mathrm{g}_{\mathrm{m} 7}-\mathrm{Y}_{8}\right)\left(\mathrm{g}_{\mathrm{m} 8}+\mathrm{Y}_{7}\right)
\end{aligned}
$$

By substituting (32), (35), (47), (49) and (58) in (38), we obtain:

$$
\frac{\mathrm{v}_{\text {reg }}}{\mathrm{v}_{\mathrm{dd}}}=\frac{\left(\mathrm{g}_{\mathrm{m} 5}+\mathrm{g}_{\mathrm{m} 6}+\mathrm{Y}_{6}+\mathrm{C}_{\mathrm{gd} 6} \mathrm{~s}\right) \mathrm{N}_{2}(\mathrm{~s}) \mathrm{D}_{3}(\mathrm{~s}) \mathrm{D}_{1}(\mathrm{~s})}{\mathrm{D}_{4}(\mathrm{~s})-\left[\mathrm{D}_{5}(\mathrm{~s})+\mathrm{D}_{6}(\mathrm{~s})+\mathrm{D}_{7}(\mathrm{~s})+\mathrm{D}_{8}(\mathrm{~s})\right]}
$$

Where,

$$
\begin{aligned}
& \mathrm{D}_{3}(\mathrm{~s})=\left[\mathrm{Y}_{\mathrm{out}}+\left(\mathrm{C}_{\mathrm{gd} 5}+\mathrm{C}_{\mathrm{gs} 5}\right) \mathrm{s}\right]\left(\mathrm{Y}_{1}+\mathrm{Y}_{10}+\mathrm{R}_{2}^{-1}\right) \mathrm{r}_{\mathrm{out}} \\
& \mathrm{D}_{4}(\mathrm{~s})=\mathrm{N}_{4}(\mathrm{~s}) \mathrm{D}_{3}(\mathrm{~s}) \mathrm{D}_{1}(\mathrm{~s}) \mathrm{D}_{2}(\mathrm{~s})
\end{aligned}
$$




$$
\begin{aligned}
& \mathrm{D}_{5}(\mathrm{~s})=\mathrm{D}_{1}(\mathrm{~s}) \mathrm{D}_{3}(\mathrm{~s})\left[\frac{\mathrm{D}_{2}(\mathrm{~s}) \mathrm{Y}_{4}\left(\mathrm{~g}_{\mathrm{m} 4}+\mathrm{Y}_{4}\right)}{\left(\mathrm{Y}_{4}+\mathrm{Y}_{9}\right)}+\mathrm{N}_{3}(\mathrm{~s})\left(\mathrm{g}_{\mathrm{m} 6}+\mathrm{C}_{\mathrm{gd} 5} \mathrm{~s}\right)\right] \\
& \mathrm{D}_{6}(\mathrm{~s})=\mathrm{D}_{1}(\mathrm{~s}) \mathrm{D}_{2}(\mathrm{~s}) \mathrm{Y}_{1}\left(\mathrm{~g}_{\mathrm{m} 1}+\mathrm{Y}_{1}\right) \mathrm{r}_{\text {out }}\left[\mathrm{Y}_{\mathrm{out}}+\left(\mathrm{C}_{\mathrm{gd} 5}+\mathrm{C}_{4}\right) \mathrm{s}\right] \\
& \mathrm{D}_{7}(\mathrm{~s})=\mathrm{D}_{1}(\mathrm{~s}) \mathrm{D}_{2}(\mathrm{~s})\left(\mathrm{g}_{\mathrm{m} 5}+\mathrm{C}_{4} \mathrm{~s}\right)\left[\mathrm{A}_{\mathrm{v}}\left(\mathrm{g}_{\mathrm{m} 1}+\mathrm{Y}_{1}\right)+\mathrm{r}_{\mathrm{out}}\left(\mathrm{Y}_{1}+\mathrm{Y}_{10}+\mathrm{R}_{2}^{-1}\right) \mathrm{C}_{4} \mathrm{~s}\right] \\
& \mathrm{D}_{8}(\mathrm{~s})=\mathrm{N}_{1}(\mathrm{~s}) \mathrm{D}_{2}(\mathrm{~s})\left\{\mathrm{r}_{\mathrm{out}} \mathrm{Y}_{1} \mathrm{R}_{2}^{-1}\left[\mathrm{Y}_{\mathrm{out}}+\left(\mathrm{C}_{\mathrm{gd} 5}+\mathrm{C}_{4}\right) \mathrm{s}\right]+\mathrm{Y}_{3} \mathrm{D}_{3}(\mathrm{~s})+\left(\mathrm{g}_{\mathrm{m} 5}+\mathrm{C}_{4} \mathrm{~s}\right) \mathrm{A}_{\mathrm{v}} \mathrm{R}_{2}^{-1}\right\}
\end{aligned}
$$

Note that $g_{m i}$ represents the small signal source-drain conductance of the MOSFET $M_{i}$ and $Y_{i}$ represents the equivalent admittance for the shunt connection of the impedance of the capacitor and a resistor.

By substituting (35) and (62) in (28), we obtain:

$$
\operatorname{PSRR}(s)=\frac{\left(g_{m 5}+g_{m 6}+Y_{6}+C_{g d 6} s\right) N_{2}(s) D_{3}(s) N_{1}(s)}{D_{4}(s)-\left[D_{5}(s)+D_{6}(s)+D_{7}(s)+D_{8}(s)\right]}
$$

The expression of the PSRR(s) shows that its transfer function has 7 poles and 7 zeros, and consequently the transient response is convergent and the proposed circuit system is stable.

The expression of low frequency PSRR is obtained by replacing $\mathrm{s}=0$ in all the terms containing the complex variable s. Thus,

$$
\operatorname{PSRR}(0)=\frac{\left(g_{m 5}+g_{m 6}+g_{06}\right) N_{2}(0) D_{3}(0) N_{1}(0)}{D_{4}(0)-\left[D_{5}(0)+D_{6}(0)+D_{7}(0)+D_{8}(0)\right]}
$$

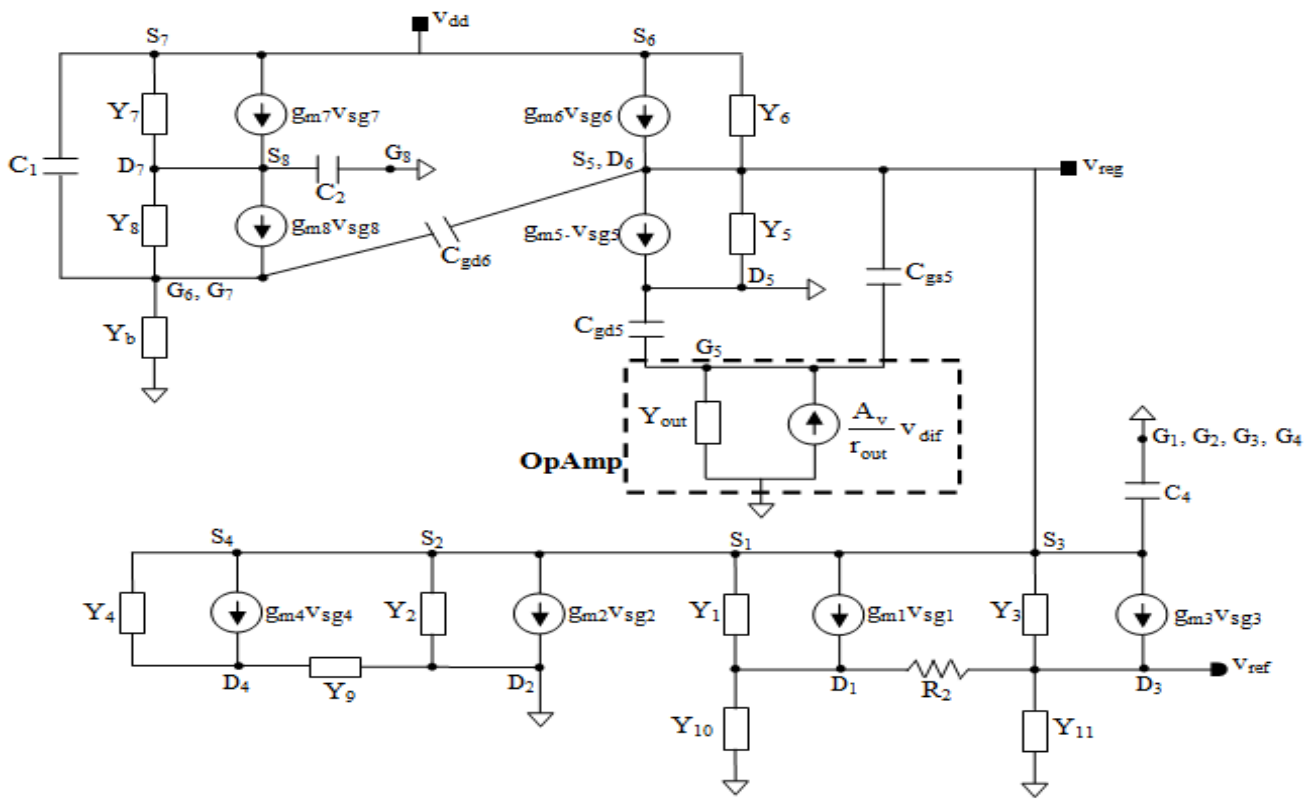

Figure 5. High frequency small signal model of proposed sub-1V BGVR

\section{SIMULATION RESULTS AND DISCUSION}

The proposed design of sub-1V bandgap voltage reference using the opamp based $\beta$-multiplier with resistive division configuration was simulated in $0.18-\mu \mathrm{m}$ standard CMOS technology using Cadence Virtuoso Spectre Simulator. The proposed circuit generates an output voltage reference VREF of $634.6 \mathrm{mV}$ at $27^{\circ} \mathrm{C}$ when the supply voltage is set to $1.8 \mathrm{~V}$. Figure 6 showns the variation of the output voltage reference 
over temperature range $-40^{\circ} \mathrm{C}$ to $140^{\circ} \mathrm{C}$ for different values of the supply voltage VDD, the maximum value of the temperature coefficient of VREF is less than $36 \mathrm{ppm} /{ }^{\circ} \mathrm{C}$ with a minimum supply voltage of $1.2 \mathrm{~V}$. As it is shown in Figure 7, the DC value of PSRR is $-93 \mathrm{~dB}$ whene the supply voltage is $1.8 \mathrm{~V}$. The measurement line regulation of VREF is $104 \mu \mathrm{V} / \mathrm{V}$ as is it shown in Figure 8. As it is shown in Figure 9, the two input voltages of the opamp have exactly the same value witch is equal to $0.6255 \mathrm{~V}$ whene the supply volage varies from $1.2 \mathrm{~V}$ to $1.8 \mathrm{~V}$ and therefore the error introduced by the input offset voltage of the opamp is eliminated.

The layout of the proposed sub-1V bandgap voltage reference circuit is shown in Figure 10. For resistors implementation, the non-silicide $\mathrm{P}+$ poly-resistor type is chosen wich has a very low temperature coefficient in order to ensure robustness of the circuit to variations in temperature and voltage. The layout area is $0.0337 \mathrm{~mm} 2$.

Table 1 summarizes performance characteristics of the proposed sub-1V BGVR and comparison with related works is given. As it is shown in Table 1, the proposed circuit provides a high value of the PSRR at high frequencies ranging from $1 \mathrm{MHz}$ up to $10 \mathrm{MHz}$, which is significantly higher than the value found in the related work see Table 1 .

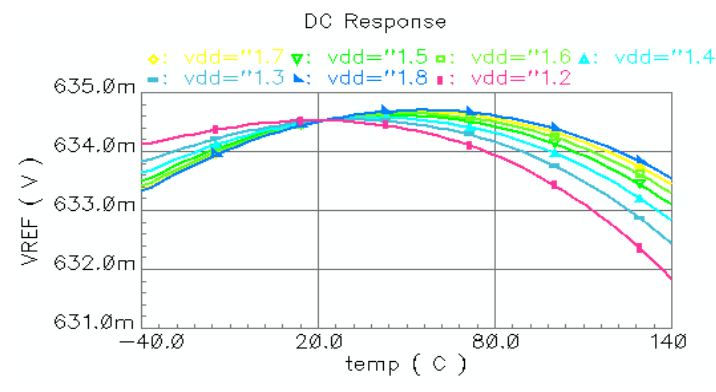

Figure 6. Simulated temperature dependence of output voltage reference for different values of power supply voltage

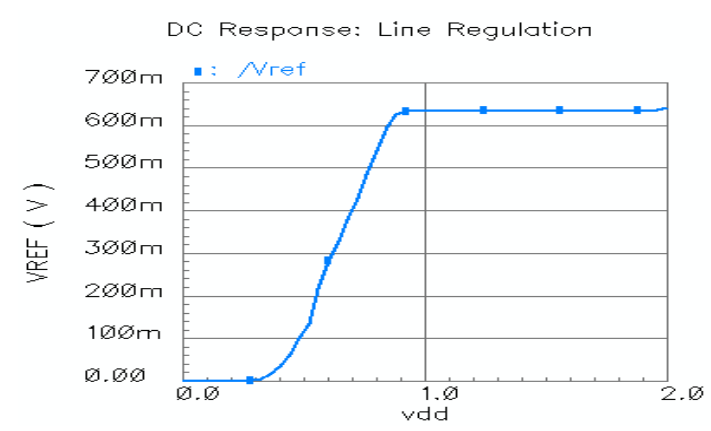

Figure 8. Simulated line regulation of the proposed sub-1V BGVR

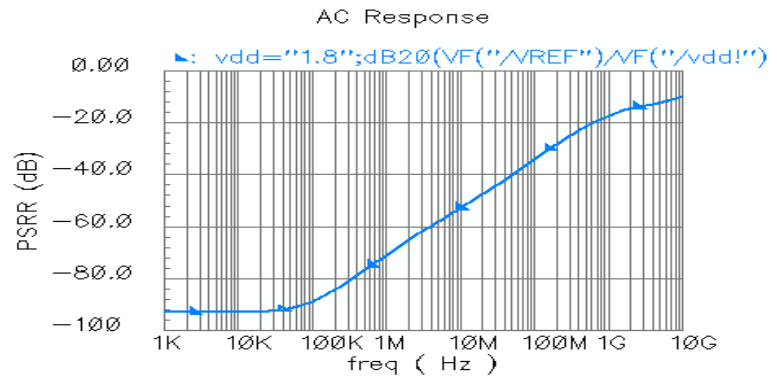

Figure 7. Simulated PSRR of the proposed sub-1V BGVR

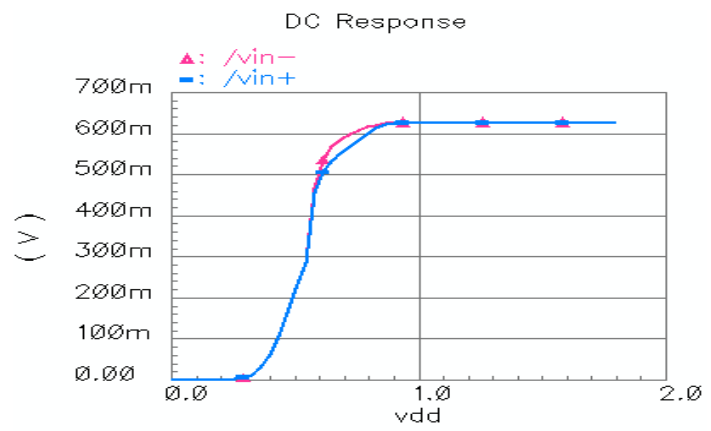

Figure 9. Simulation of the error introduced by input offset voltage of the OpAmp in proposed sub-1V BGVR

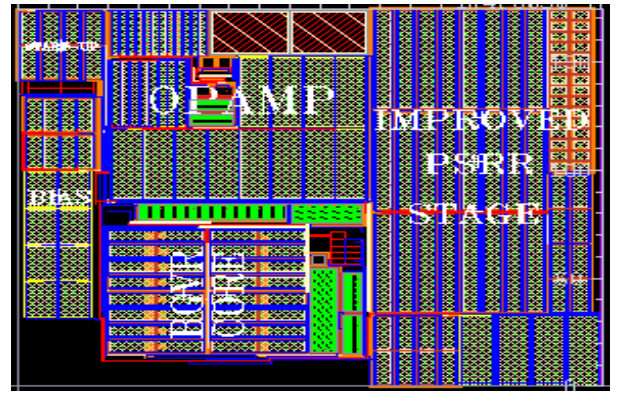

Figure 10. Layout of proposed sub-1V BGVR reference 
Table 1. Performance of Proposed Sub-1V BGVR and Comparison

\begin{tabular}{|c|c|c|c|c|c|c|}
\hline Performance & [14] & [15] & [16] & [17] & [18] & This work \\
\hline Technology (CMOS) & $0.09 \mu \mathrm{m}$ & $0.13 \mu \mathrm{m}$ & $0.18 \mu \mathrm{m}$ & $0.18 \mu \mathrm{m}$ & $0.5 \mu \mathrm{m}$ & $0.18 \mu \mathrm{m}$ \\
\hline $\mathrm{V}_{\mathrm{DD}, \min }(\mathrm{V})$ & 2.7 & 0.93 & 1.2 & 2.5 & 1.2 & 1.2 \\
\hline $\mathrm{V}_{\mathrm{REF}}(\mathrm{V})$ & 0.21398 & 0.594 & 0.681 & 1.194 & 0.561 & 0.6346 \\
\hline $\mathrm{TC}\left(\mathrm{ppm} /{ }^{\circ} \mathrm{C}\right)$ & 6.07 & 18.2 & 2.235 & 6.51 & & 22.3 \\
\hline Temperature operation range $\left({ }^{\circ} \mathrm{C}\right)$ & -20 to 120 & -30 to 80 & -50 to 115 & -25 to 80 & -20 to 120 & -40 to 140 \\
\hline PSRR@1MHz & & & $>-20 \mathrm{~dB}$ & $-40 \mathrm{~dB}$ & $>-20 \mathrm{~dB}$ & $-71 \mathrm{~dB}$ \\
\hline PSRR@10MHz & & & & & & $-52.8 \mathrm{~dB}$ \\
\hline
\end{tabular}

\section{CONCLUSION}

In this paper, a novel design of sub-1V bandgap voltage reference circuit with opamp based $\beta$ multiplier and resistive divider architecture is proposed. The important contribution of this work is the obtaining of an accurate voltage reference with a high value of the PSRR in a very wide frequency range. The proposed architecture of the voltage divider has made it possible to elimlate the undesirable effect of the input offset voltage of the opamp in order to obtain a very accurate value of the output voltage reference and to improve the DC value of the PSRR. In order to reduce ripple from the supply voltage which directly influences the performance of the PSRR, an improved PSRR scheme is added to isolate the supply voltage source from the supply voltage of the operational amplifier and also the supply voltage of the BGVR core generator which allows improving the value of the PSRR in high frequency. The proposed voltage reference can be used as an internal comparison voltage in LDO regulators.

\section{REFERENCES}

[1] Suresh Alapati, Patri Sreehari Rao. A Low Quiescent Current Fast Settling Capacitor-less Low Drop Out Regulator Employing Multiple Loops. Indonesian Journal of Electrical Engineering and Computer Science (IJEECS), Vol. 10, No. 3, pp. 1070-1079, June 2017.

[2] G.G.Raja Sekhar, Basavaraja Banakara. Performance of Brushless DC Drive with Single Current Sensor Fed from $P V$ with High Voltage-Gain DC-DC Converter. International Journal of Power Electronics and Drive System (IJPEDS), Vol. 9, No. 1, pp. 33 45, March 2018.

[3] Widlar, Robert J. New Developments in IC Voltage Regulators. IEEE Journal of Solid State Circuits, Vol. SC-6, pp 2-7, February 1971.

[4] K.E. Kujik. A precision reference voltage source. IEEE Journal of Solid State Circuits 8 (3) p 222-226, 1973.

[5] Brokaw, Paul. A simple three-terminal IC bandgap reference. IEEE Journal of Solid State Circuits, 9 (6), pp 388-393, December 1974.

[6] B. Song, P.R. Gray. A precision curvative-compensated CMOS BG reference. IEEE Journal of Solid State Circuits, 18 (6) p 634-643, 1983.

[7] Banba, Hironori, et al. A CMOS bandgap Refrence With Sub-1-V Operation. IEEE Journal of Solid State Circuits, Vol 34, pp. 670-674, May 1999.

[8] Leung, K.N. and Mok, K.T. Sub-1-V 15ppm $/{ }^{\circ} \mathrm{C}$ CMOS Bandgap Voltage Reference Without Eequiring low threshold voltage device. IEEE Journal of Solid State Circuits, 37 (4), pp. 526-529, 2002.

[9] Ker, M.D., Chen, J.S. and Chu, C.Y. New Curvative-Compensation Technique for CMOS Bandgap Reference with Sub-1-V Operation. IEEE Journal of Solid State Circuits and Systems-II: Express Briefs, 53 (8), pp. 667-671, 2006.

[10] Ripamonti, G., et al. Low Power - Low Voltage Bandgap Refrences for Flash EEPROM Integrated Circuits: Design Alternatives and Experiments. Proceedings of ICECS 1999, Vol. 2, pp. 635-638, 1999.

[11] Jiang, Yuenming, and Lee, Edward. Design of Low-Voltage Bandgap Refrence Using Transimpedance Amplifier. IEEE Transactions on Circuits and Systems-II, Vol. 47, pp. 552-555, June 2000.

[12] Annema, Anne-Johan. Low-Power Bandgap References Future DTMOST's. IEEE Journal of Solid State Circuits, Vol 34, pp. 949-955, July 1999.

[13] C. M. Andreou, S. Koudounas, and J. Georgiou. A Novel Wide-Temperature-Range, 3.9ppm $/{ }^{\circ} \mathrm{C}$ CMOS Bandgap Reference Circuit. IEEE Journal of Solid-State Circuits, vol.47, no. 2, pp. 574-581, Jan. 2012.

[14] Keith R. Francisisco and Jefferson A. Hora. Very Low Bandgap Voltage Reference With High PSRR Enhancement Stage Implemented in 90nm CMOS Process Technology for LDO Application. IEEE International Conference on Electronics Design, Systems and Applications, 2012.

[15] Jianhui Wu, Chao Chen, Haifeng Shen, Chen Huang, Hao Liu. A High PSRR CMOS voltage reference with 1.2V operation. Analog Integrated Circuits and Signal Processing, Vol. 77, No. 1, pp. 79-86, october 2013.

[16] Zhou Qianneng, Xue Rong, Li Hongjuan, Lin Jinzhao, Li Qi, Pang Yu, Li Guoquan. A Low-Voltage High PSRR and High Precision CMOS Bandgap Reference. TELKOMNIKA Indonesian Journal of Electrical Engineering, Vol. 12, No. 5, pp. 3832-3840, May 2014. 
[17] Xiuhan Li and Hanru Zhang. A High PSRR Voltage Reference for High Efficiency Power Management Circuits of MEMS Energy Harvesters. Journal of Applied Science and Engineering, Vol. 17, No.2, pp. 111-116, 2014.

[18] Yun-wu Zhang, Jing Zhu, Wei-feng Sun, Guodong Sun, Sheng-li Lu. A novel sub-1V bandgap reference with offset compensated techniques. Analog Integrated Circuits and Signal Processing, Vol. 78, No. 2, pp. 391-397, February 2014.

[19] Behzad Razavi. Design Of Analog CMOS Integrated Circuit. Second Edition, 2017 by McGraw-Hill Education.

[20] Phillip E. Allen, Douglas R. Holberg. CMOS Analog Circuit Design. Second Edition, February 2002.

[21] G. Giustolisi, G. Palumbo. A Detailed Analysis of Power Supply Noise Attenuation in Bandgap Voltage References. IEEE Transactions On Circuits and System-I: Fundamental Theory and Applications, vol. 50, No. 2, p. 185-197, February 2003.

\section{BIOGRAPHIES OF AUTHORS}
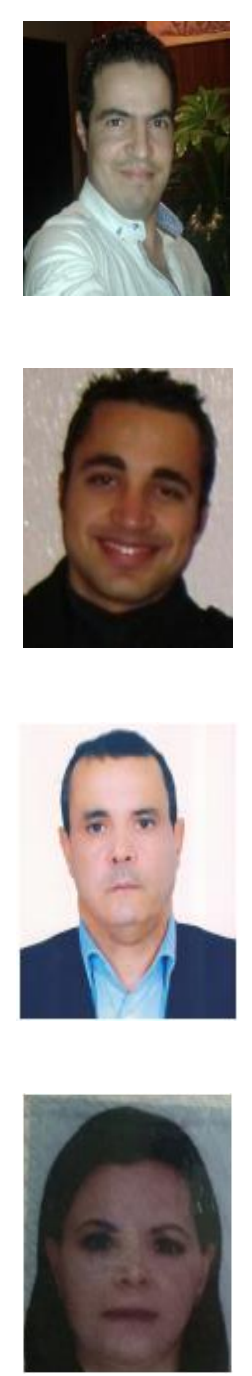

Anass Slamti received the Master Degree specialized in Sciences of Computer and Systems from the SMBA University, Fez Morocco in 2009. Since 2010, he works as a teacher of physics in secondary education qualifying. His current research interests in analog and mixed integrated circuits. Currently he prepared the $\mathrm{PhD}$ Thesis in integrated power supply circuits for smart handhelds devices.

Youness MEHDAOUI received the $\mathrm{PhD}$ Thesis in electrical engineering from the SMBA University, Fez Morocco in 2014. His current research interests in signal processing, embedded systems, analog and mixed integrated circuits.

Driss Chenouni received the Ph.D. degree in physics from the University of Montpellier II, France, in 1989, and the State Doctor's degree from the University of Fes, Morocco, in 1996. $\mathrm{He}$ is currently a Lab director of computering and interdisciplinary physics (L.I.P.I), at (E.N.S.F), and a Director of the Ecole Normale Supérieur at Sidi Mohammed Ben Abdellah University (USMBA), Fez, Morocco. His current research interests include Multi-Agent systems, Enterprise Architecture, Modeling, Web services, Autonomic computing, image processing and indexation of old manuscripts.

Zakia Lakhliai received the Ph.D. degree in physics from the University of Montpellier II, France, in 1987, and the State Doctor's degree from the University of Fes, Morocco, in 1996. She is currently a member of Lab of computering and interdisciplinary physics (L.I.P.I), at (E.N.S.F), and a Professor in the Superior School of technology (E.S.T.F.) at Sidi Mohammed Ben Abdellah University (USMBA), Fez, Morocco. Her current research interests signal and image processing, analog and mixed integrated circuits. 